\title{
Computer Supported Collaborative Learning and Higher Order Thinking Skills: A Case Study of Textile Studies
}

\author{
Ada W. W. MA \\ Department of Mathematics, Science, Social Sciences and \\ Technology, The Hong Kong Institute of Education, \\ Hong Kong SAR, China
}

ama@ied.edu.hk

\begin{abstract}
The scarcity of readily usable instruments to research learning in Computer Supported Collaborative Learning (CSCL) environments has posed a great challenge to devise appropriate analytical tools to investigate how individuals change their understanding or create a new personal construction of know ledge as a result of social interaction and negotiation within the group. Given this scenario, the Activity System Model(Engeström, 1987), based on a soc io-cultural perspective, was adopted as a framework for analysing the quality of a CSCL community in this research project. Data were analysed to examine how interactivity had contributed to the fostering of higher order thinking skills in the CSCL community. Findings of this study conf irmed that there was a positive correlation between the quality of collaborative process engaged by groups and the quality of cognitive skills fostered. High levels of social interaction and collaboration contributed to the establishment of a community of learning, nurturing a space for fostering higher order thinking through co-creation of know ledge processes. Lessons learnt and limitations of the investigation in this study in light of the methodological issues relating to coding reliability and difficulties in translating Chinese text involved in the CSCL for computerized coding process were discussed as well.
\end{abstract}

Keywords: CSCL, higher order thinking skills, textile studies

\section{Literature Review}

There is a growing body of literature providing accounts of research that support the educational value of Computer Supported Collaborative Learning (CSCL). The results of a meta-analysis on CSCL reveal that using collaborative techniques with technology could increase high-level

Material published as part of this publication, either on-line or in print, is copy righted by the Informing Science Institute. Permission to make digital or paper copy of part or all of these works for personal or classroom use is granted without fee provided that the copies are not made or distributed forprofit or commercial advantage AND that copies 1) bear this notice in full and 2) give the full citation on the first page. It is permissible to abstract these works so long as credit is given. To copy in all other cases or to republish or to post on a server or to redistribute to lists requires specific permission and payment of a fee. Contact Publisher@InformingScience.org to request redistribution permission. thinking skills, social interactions, critical reflective capabilities, and creativity (Lehtinen, Hakkarainen, Lipponen, Rahikainen, \& Muukkonen, 2003; Smith, 2003; Warschauer, 1997).

Several empirical experiments offer some evidence that the well-known CSCL environments like Computer-Supported Intentional Learning (CSILE) and Belvedere have proved to be helpful for higher order cognitive 
processes and collaborative know ledge-building (Lamon, Reeve, \& Scardamalia, 2001; Lehtinen et al., 2003). The learning efficiency of CSCL is further confirmed by various studies (Dewiyanti, Brand-Gruwel, Jochems, \& Broers, 2007; Ewing \& Miller, 2002; Gillies, 2004; Nachmias, Mioduser, Oren, \& Ram, 2000; Resta \& Laferriere, 2007; Shellens \& Valcke, 2005) as, through this articulation process, old and new know ledge was integrated and new knowledge could be expanded to other applications. In these studies, CSCL appears to engage students to participate in in-depth inquiry over substantial periods of time and to provide socially distributed cognitive resources for comprehension monitoring and other meta-cognitive activities. This, in turn, allows students to become aware of their conceptual advancement, as well as of changes in their practices of inquiry.

Introducing a computer environment to collaborative learning can also improve the amount and quality of social interaction among learners and between educators and learners as these tools make the sequence of interaction events more visible for participants, opening better possibilities for mutual understanding. For example, a study conducted by Häkkinen, Järvelä, and Byman (2001) showed that the participants had mutual negotiations in the ir web-based communication and they discussed issues from a variety of different viewpoints. With the help of technology such as groupware, it has been possible to create interactive processes in which learners are consciously constructing new knowledge on an inter-subjective or social level (Kreijins \& Kirschner, 2002).

In recent research, considerable attention has been paid to theoretical debate in the field of collaborative learning; however, little attention has been paid to issues of methodology and analysis methods to evaluate the quality of the collaborative learning community (De Wever, Schellens, Valcke, \& Van Keer, 2006; Gunawardena, Lowe, \& Anderson, 1997; Gunawardena, Carabajal, \& Lowe, 2001; Strijbos, Martens, Prins, \& Jochems, 2006) as they have been confronted with a range of problems. One of the problems of researching learning in CSCL environments is perhaps the realisation of the complexity of learning interactions being probed (De Laat, 2002; Lally, 2002; Lally \& De Laat, 2002). The problem can be easily understood as it relates to the analytical tools used with the complicated procedures for content analys is. Content analysis is cumbersome and time consuming and the choice of coding categories is a complex issue in itself (Lally \& De Laat, 2002). In this regard, extensive effort was made to devise an appropriate content analysis scheme for this study to illuminate interaction patterns and quality of the discourse of a CSCL community.

\section{Methodology}

Activity Theory provides educators with a practical and holistic approach to the evaluation of a CSCL community (Hew \& Cheung, 2003). To make the content analysis valid, there should be a concrete link between the analys is categories and the theoretical framework. Without a theoretical model of the collaborative learning process it is impossible to ident if y empirical indicators that will form the basis of a coding instrument as a standard against which to evaluate whether effective learning is occurring in the online discussions (De Wever et al., 2006; Gunawardena et al., 2001). In light of the Activity System Model (Engeström, 1987), the following section will identify useful and meaningful indicators to evaluate whether or not effective learning is taking place in the technology-enhanced environment.

\section{Evaluation Questions}

The subject-community-object triad within the activity system describes how the participants of an asynchronous online discussion forum and the surrounding learning community collaborate to act on the object (Hew \& Cheung, 2003). To reveal how individuals change their understanding, or co-construct new knowledge as a result of social interaction within the group, possible evaluation questions on interactivity and cognitive presence will be addressed as follows. When conducting their CSCL activities, the following questions arise: 
What is the level of participation among the subject?

Is knowledge constructed within the group by means of the exchanges among participants?

Do participants change their understanding or create newly constructed knowledge as a result of interactions within the group?

What quality of cognitive skills do the learners exhibit?

To answer these evaluation questions and to investigate the interrelationship between the interactivity and cognitive presence within a CSCL community, a combination of instruments were built to fit with the data analysis to reflect a complete and meaningful picture of the CSCL community. Each instrument adopted has its own value and focuses attention on different aspects of the learners' involvement and thinking as evidenced in the online community. The nature of the learning interactions among participants in a CSCL context is sometimes very complex and multidimensional and it is not easy to research using any single method (Lally \& De Laat, 2002), hence the range of techniques employed in this study.

\section{Proposed Content Analysis Scheme}

The content analysis scheme comprising two different instruments based on three aspects is listed in Table 1 as follows:

Table 1 Proposed content analys is scheme

\begin{tabular}{lll}
\hline Instruments adopted & Aspect to be evaluated & Unit of analys is \\
\hline & $\begin{array}{l}\text { Level and intensity of par- } \\
\text { tic ipation }\end{array}$ & Usage statistics \\
\hline $\begin{array}{l}\text { Henri (participative presence) } \\
(1992)\end{array}$ & Nature of interaction & Thematic unit \\
\hline Gunawardena et al. (1997) & $\begin{array}{l}\text { Cognitive presence - } \\
\text { Social construction of } \\
\text { know ledge; } \\
\text { Higher order thinking skills }\end{array}$ & Thematic unit \\
\hline
\end{tabular}

France Henri (1992) was a pioneer in utilising content analys is to evaluate the quality of online learning communities and her work has laid the foundation for subsequent research. Henri's analytical framework consists of five dimensions: namely, participative, social, interactive, cognitive, and meta-cognitive. The major strength of her model is that it focuses on the social activity and the interactivity of individuals in a group, at the same time giving a picture of the cognitive and meta-cognitive process of those individuals. Replicating studies conducted by Henri on the nature of interaction is mainly due to the fact that it is easier to conduct, for extensive research literature exists on this model helping others understand its implementation.

Gunawardena et al. (1997) initiated the interaction analysis for examining social construction of know ledge, reflecting one of the key characteristics of CSCL, to counteract the limitations of Henri's (1992) model in which the progression of ideas being reflected at different phases of the interaction is not captured. The replication of Gunawardena et al.'s (1997) model on elic iting evidence for the social construction of knowledge is justified by its merits offered: (a) it focuses on interaction as the vehicle for the co-construction of knowledge, (b) it focuses on the overall pattern 
of knowledge construction emerging from a conference, (c) it is most appropriate in a collaborative learning context, (d) it is a relative ly straightforward schema, and (e) it is adaptable to a range of teaching and learning contexts. Marra, Moore, and Klimczak (2004, p. 39) further affirm that it provides "a more holistic view of discussion flow and know ledge construction." Intra-coder reliability is reported in their study as well. As for the unit of analysis, a thematic unit instead of a message unit was adopted to make the analysis consistent with all sorts of interactions.

\section{Unit of Analysis}

To conduct the content analysis, a unit of analysis had to be determined for coding and analysis. A unit of analysis includes: (a) each individual sentence, (b) a consistent theme or idea in a message (unit of meaning), and (c) an entire message a student posts at a certain moment in the discussion. In this study, a thematic unit based on Henri's (1992) model was utilised as the unit of analys is in the online learning community. A thematic unit is "a single thought unit or idea unit that conveys a single item of information extracted from a segment of content" (Budd, Thorp, \& Donohew, 1967, p. 34). Henri (1992, p. 134) justifies this approach by arguing that:

it is absolutely useless to wonder if it is the word, the proposition, the sentence or the paragraph which is the proper unit of meaning, for the unit of meaning is lodged in meaning ... It is the intelligence of text, which rests upon a logical decomposition which will make the appropriate divisions apparent.

The essential factor of content analysis is not the form but the meaning. Supporters of the "unit of meaning" argue that separate segmentation and coding is irrelevant because segmentation depends on the coding categories.

There have been a lot of discussions over the methodological issues of reliability and replicability on units of analysis. The choice for a unit of analysis to achieve objectivity depends on its intra-rater reliability, inter-rater reliability, and replicability (De Wever et al., 2006; Gunawardena et al., 2001; Rourke, Anderson, Garrison, \& Archer, 2001) and there is no general agreement yet. Strijbos et al. (2006, p. 36) concluded that "choosing a unit of analys is can be guided by accepted practices, but the unit should be clearly defined and unit boundary overlap should be limited and computed."

\section{Content Analysis Procedures}

Content analys is comprised four basic steps: (a) a compilation or selection of the transcripts for analysis, (b) development of a coding scheme and the training of coders to implement the protocol, (c) comparison of coding decisions for inter-rater reliability, and (d) an analysis and reporting of the coded data either in describing the variables or identifying the relationships between variables (Gunawardena et al., 2001).

The actual analys is of the postings was carried out in two parts in this study. The online postings were first studied and divided into the appropriate units of analysis, that is, thematic units. The second part involved the use of the content analysis scheme with various chosen instruments on the identified units of analys is.

Inter-coder reliability can be defined as "the extent to which different coders, each coding the same content, come to the same coding decisions" (Rourke et al., 2001, p. 4). In the current context, the researcher and the research assistant conducted the coding independently and then compared the results. A comparison of the results showed the level of agreement between the two scores was $95 \%$ on the unit of analysis, $98 \%$ on the nature of participation, and $70 \%$ on phases of social construction of know ledge. A high percentage of agreement on deriving the thematic unit for analysis may be due to the fact that it is not difficult to de lineate a unit of idea/meaning from Chinese 
messages with its distinctive language structure. The reliability of classifying message content for the phases of knowledge construction was somewhat unsatisfactory. A closer examination of the major discrepancies fell in the categories of discovery of dissonance (Phase II) and negotiation of meaning (Phase III).

\section{Data Analysis and Findings}

Six groups of 4-5 students were involved in a 7 week project, investigating the latest development of textile fibres and fabrics. Students were required to conduct intra-group exploration of the ir chosen fibre or fabric in terms of its structure, properties, end-uses and care, and submit a final PowerPoint presentation for inter-group peer assessment and written feedback. Intra-groups were encouraged to have online discussions with their group members during the process and had to submit reflective journals bi-weekly. The instructor took the role of a facilitator during the process and provided the overall feedback on learners' participation in the 7th week. Out of the six groups of students, students from groups A, B, E, and F were a mixed group of learners who were in-service teachers while groups $\mathrm{C}$ and $\mathrm{D}$ comprised full-time students.

\section{Interactivity}

The level and intensity of participation can be analysed from the usage statistics, comprising the number of messages posted, the frequency of access, the number of messages per student, and the number of threads and messages per thread. Such rich sources of data illuminate how collaborative learning conditions were generated and maintained. The intra-group messages were collected and a detailed analys is on interactivity was conducted.

\section{Level of participation - Messages posted}

The participants' frequency of engagement varied considerably. As shown in Table 2 and Figure 1, amongst groups A, B, E, and F, it was found that Group B posted the most valid messages (276) compared with Group E who posted the least (64) messages over the project period. As for two groups of full-time student-teachers, Group C posted the most valid messages (64), nearly twice that of Group D (34).

\section{Table 2 Frequency of valid messages posted by groups A-F}

\begin{tabular}{lll}
\hline & Total number of mess ages posted & Valid messages \\
\hline Group A & 115 & 109 \\
\hline Group B & 278 & 276 \\
\hline Group C & 67 & 64 \\
\hline Group D & 34 & 34 \\
\hline Group E & 66 & 64 \\
\hline Group F & 86 & $78^{3}$ \\
\hline
\end{tabular}

\footnotetext{
${ }^{1}$ Group B and E continued to utilise the forum after the project period and they posted additional 44 and 73 messages respectively.

${ }^{2}$ Students might have pressed the "submit" button twice before refreshing their browsers, thus some duplicat ed messages were found.
} 


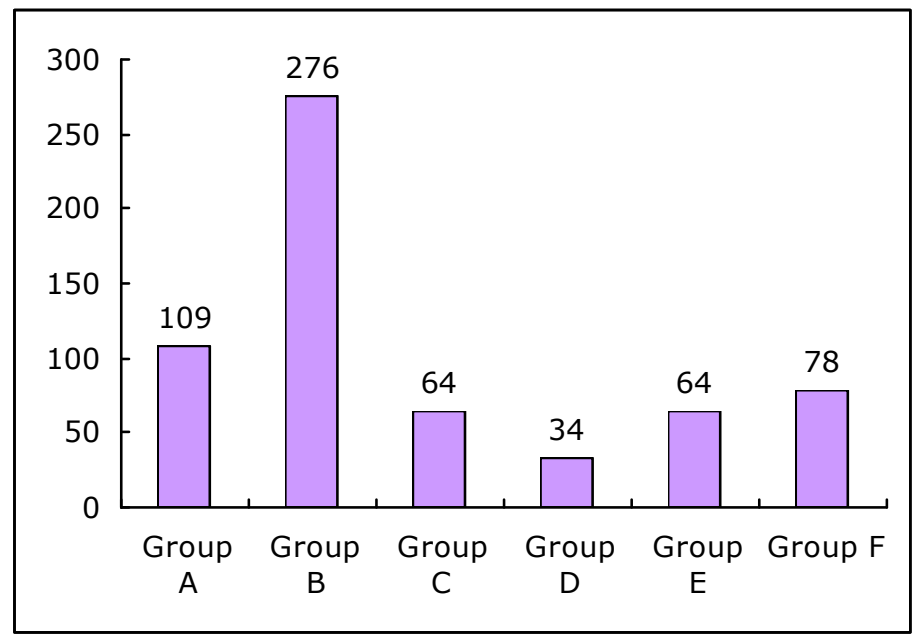

Figure 1 Numbers of valid messages posted by groups A-F

\section{Level of participation - Structure of participation}

The structure of the online discussion was observed by recording the time of the day and day of the week for each message. The data generated indicated the time pattern for each group's collaboration and at what stage their collaboration came to maturity.

Time of day posting message. Tables 3 and 4 show the intra-group divergent frequencies of message creation during the day. It was identified that Groups A, B, and F posted the majority of messages during the period of 9.00 p.m. to 2.00 a.m., which was expected as they were posted after their teaching duties at school and after taking care of their family business in the evening. Group $\mathrm{E}$, however, displayed a very distinctive pattern of posting time; it was between 8:00 a.m. to 10:00 a.m., which aligned with their free periods of teaching at school. They appeared reluctant to continue discussions after work.

As for the full-time groups, Group $\mathrm{C}$ shared a similar pattern with groups $\mathrm{A}, \mathrm{B}$, and $\mathrm{F}$ in terms of posting time. It was assumed that the members were busily engaged in the ir lectures during the daytime and chose to communicate at night. Group D tended to post their messages between 12:00 noon to 1:00 p.m. which implied that these members were only willing to communicate during their lunch time at the Institute.

Table 3 Peak hours of users posting their messages

\begin{tabular}{ll}
\hline & Peak Hours \\
\hline Group A & 10 p.m. to 12 a.m. \\
\hline Group B & 10 p.m. to 11 p.m. \\
\hline Group C & 9 p.m. to 10 p.m. \\
\hline Group D & 12 noon. to 1 p.m. \\
\hline Group E & 8 a.m. to 10 a.m. \\
\hline Group F & 12 a.m. to 2 a.m., 8 a.m. to 10 a.m. \& 2 p.m. to 3 p.m. \\
\hline
\end{tabular}


Table 4 Time pattern of users pos ting their messages

\begin{tabular}{|c|c|c|c|c|c|c|}
\hline & \multicolumn{6}{|c|}{ Number of messages } \\
\hline & Group A & Group B & Group C & Group D & Group E & Group F \\
\hline 12-1 am & 6 & 8 & 3 & 3 & 4 & 8 \\
\hline 1-2 am & 3 & 2 & 1 & 1 & 0 & 10 \\
\hline 2-3 am & 1 & 1 & 0 & 3 & 0 & 0 \\
\hline 3-4 am & 0 & 0 & 0 & 1 & 0 & 0 \\
\hline 4-5 am & 0 & 0 & 0 & 0 & 0 & 0 \\
\hline 5-6 am & 1 & 0 & 0 & 0 & 0 & 1 \\
\hline 6-7 am & 0 & 0 & 0 & 0 & 0 & 1 \\
\hline 7-8 am & 1 & 2 & 0 & 0 & 0 & 1 \\
\hline 8-9 am & 10 & 25 & 1 & 3 & 11 & 8 \\
\hline 9-10 am & 3 & 20 & 3 & 1 & 9 & 11 \\
\hline 10-11 am & 7 & 15 & 2 & 1 & 6 & 4 \\
\hline 11-12 pm & 3 & 13 & 0 & 0 & 2 & 6 \\
\hline 12-1 pm & 3 & 10 & 2 & 10 & 3 & 1 \\
\hline $1-2 \mathrm{pm}$ & 2 & 21 & 5 & 2 & 2 & 3 \\
\hline 2-3 pm & 5 & 20 & 3 & 1 & 1 & 9 \\
\hline 3-4 pm & 4 & 8 & 6 & 0 & 1 & 4 \\
\hline $4-5 \mathrm{pm}$ & 7 & 26 & 7 & 0 & 1 & 3 \\
\hline $5-6 \mathrm{pm}$ & 4 & 15 & 0 & 0 & 0 & 0 \\
\hline 6-7 pm & 1 & 7 & 5 & 1 & 5 & 1 \\
\hline $7-8 \mathrm{pm}$ & 2 & 1 & 6 & $\overline{0}$ & 8 & 0 \\
\hline 8-9 pm & 3 & 8 & 3 & 1 & 0 & 1 \\
\hline 9-10 pm & 4 & 5 & 9 & 0 & 3 & 1 \\
\hline 10-11 pm & 20 & 46 & 5 & 3 & 5 & 1 \\
\hline 11-12 am & 19 & 23 & 3 & 3 & 3 & 4 \\
\hline Total & 109 & 276 & 64 & 34 & 64 & 78 \\
\hline
\end{tabular}

Day of the week for posting mess ages. The distribution of number of messages per week during the 7 week project is shown in Figure 2. 


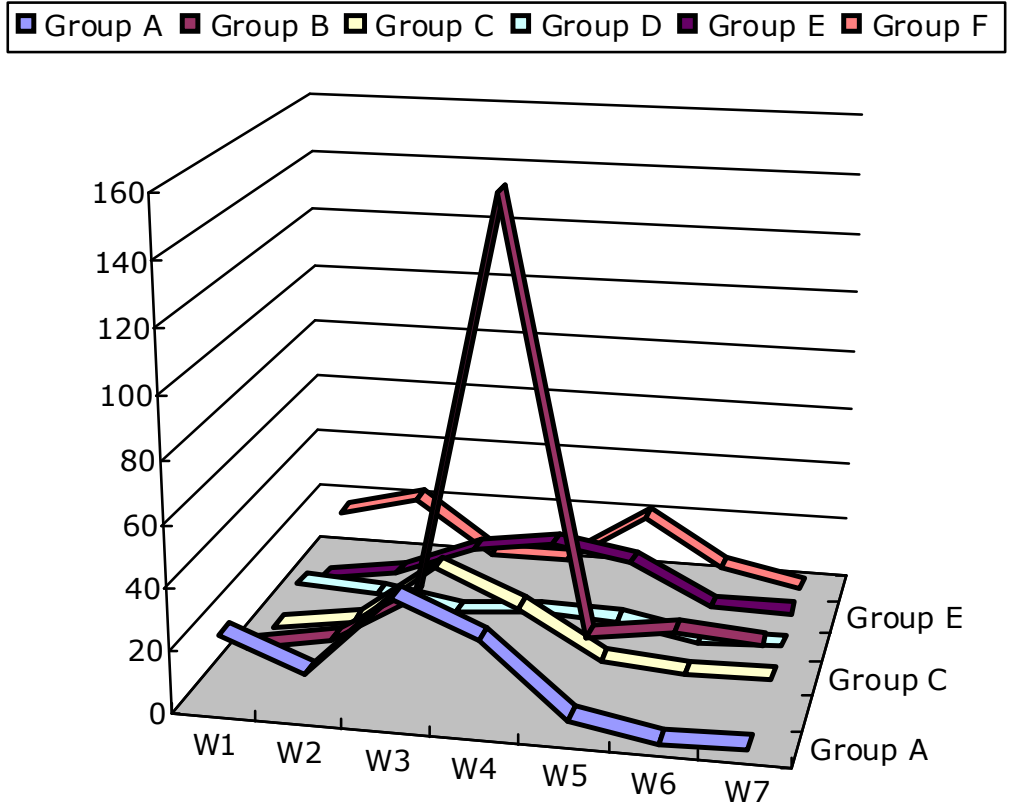

Figure 2. Distribution of messages during 7 week project

Tracking the pattern of messages over the 7 weeks revealed that the highest number of postings was in weeks 3 and 4, with the number of contributions dropping gradually during weeks 5, 6, and 7 . After the initial phase (week 1-2) when students took time to familiarise themselves with the new form of student-centred learning, the interaction entered a high intensity phase in week 3-4 during which collaborative learning conditions were fully established with information sharing and know ledge construction. In the last phase, the intensity decreased slightly reflecting the completion of the team projects and the assessment tasks. Such a pattern in the development of the collaborative learning space matched students' needs for collaboration and could thus be considered satisfactory. However, two groups displayed an interesting pattern of messages: Group D posted most messages during week 1 and 2 while Group F posted most messages at week 2 and week 5. Such differences in the pattern of message posting potentially imply different collaborative patterns among the groups and deserve further investigation.

\section{Level of participation - Intensity of participation}

The intensity of postings can be observed by means of the number of coded message units per user per group and the numbers of threaded messages posted within the group. Such information provides an indication of how collaborative learning conditions were generated and maintained.

Number of mess ages and coded mess age units per user per group. The overall posting distribution is shown in Figures 3-8. With reference to Figure 3, most of the Group A members partic ipated actively in the collaborative tasks. 


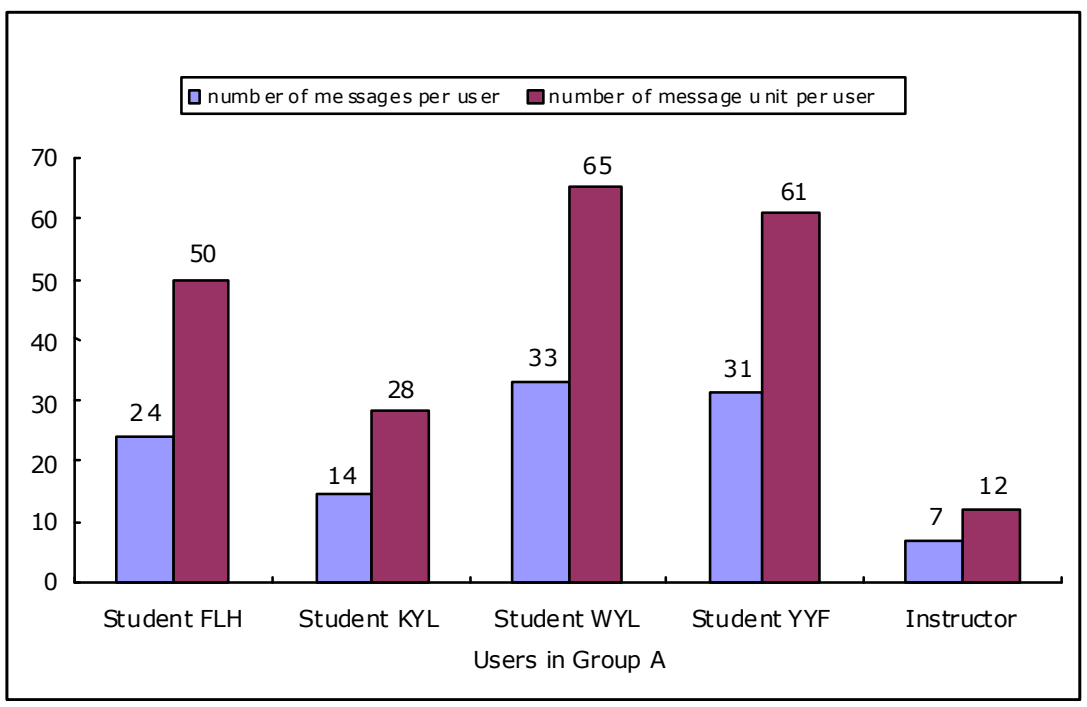

Figure 3. Number of messages and message units per user in Group A

With reference to Figure 4, the collaborative activities were widely spread among the Group B members.

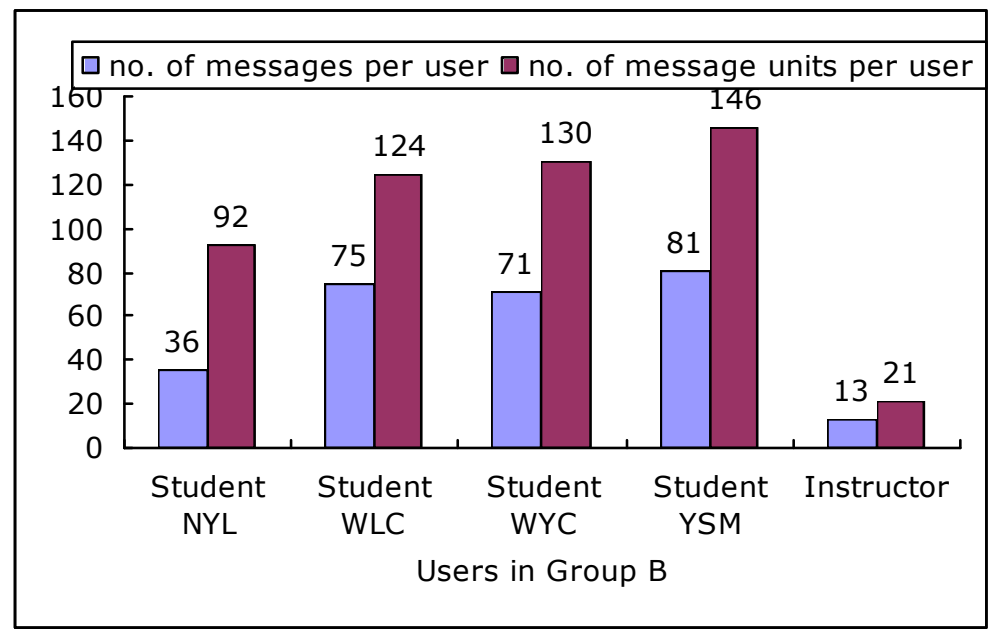

Figure 4. Number of messages and message units per user in Group B

With reference to Figure 5, most of the Group $\mathrm{C}$ students participated in the discussion with student WKH dominating while student YTL was the least active. 


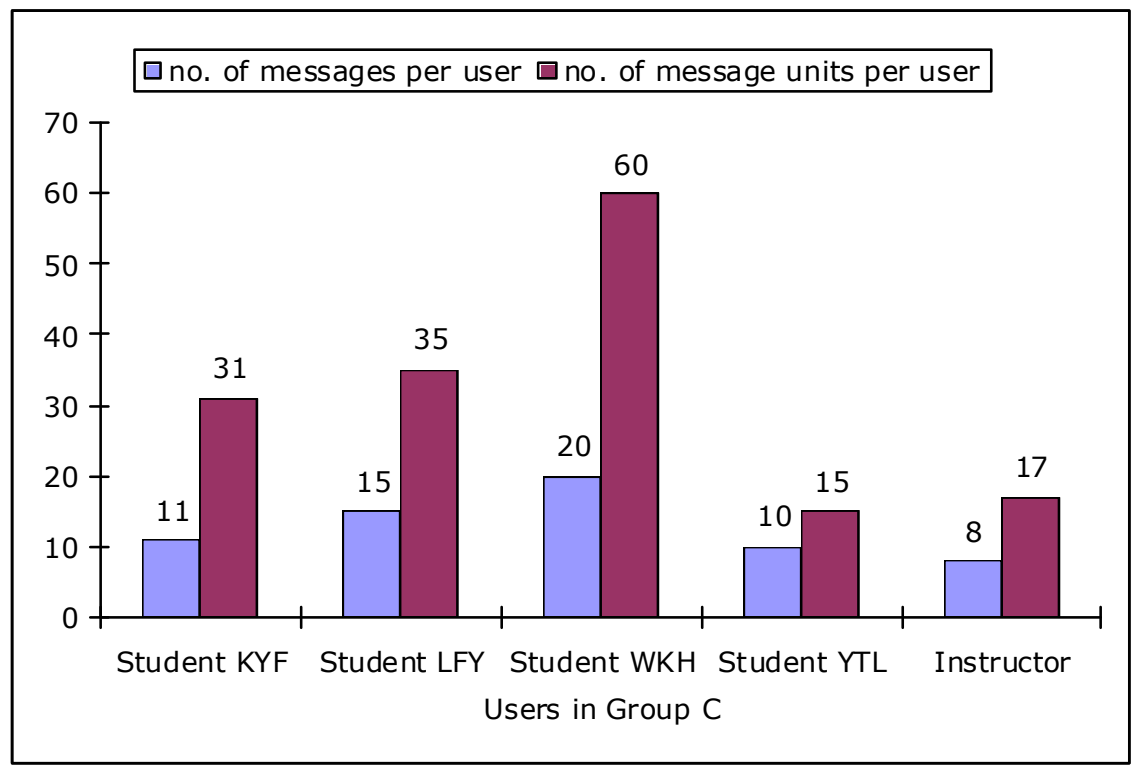

Figure 5. Number of messages and message units per user in Group C

With reference to Figure 6, most of the Group D students participated in the tasks with student WSL taking the role of leader while student WCW contributed the least to the group.

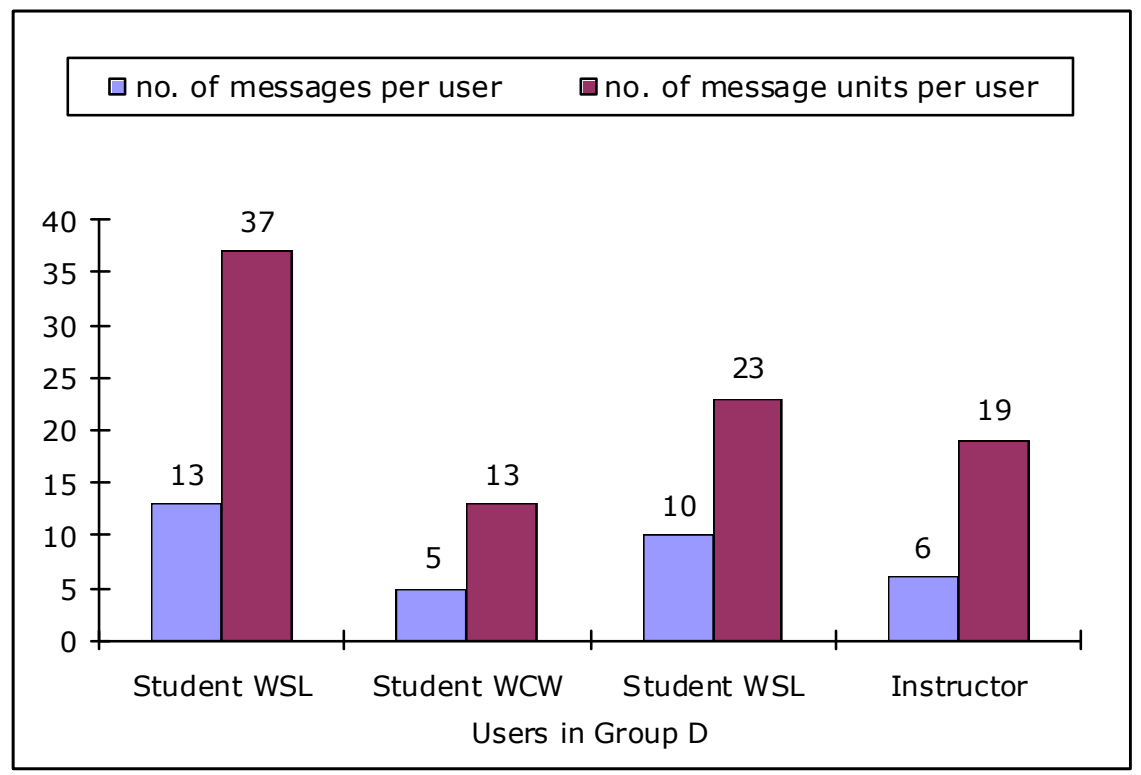

Figure 6. Number of messages and message units per user in Group D

With reference to Figure 7, the collaborative activities were not evenly distributed among the Group E members with two students taking the lead in the discussion and the rest taking fairly active part. 


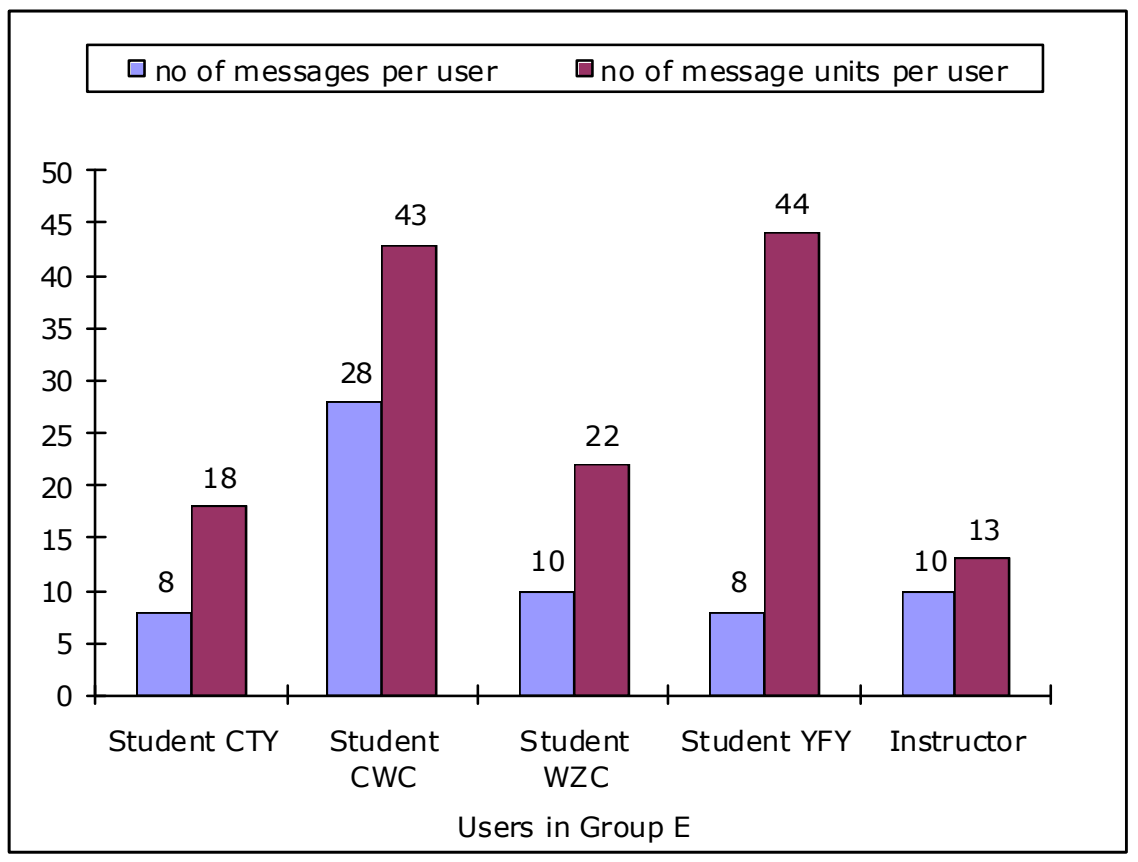

Figure 7. Number of messages and message units per user in Group E

With reference to Figure 8, the activities were not evenly distributed among the Group F learners with one learner taking the lead in the discussion.

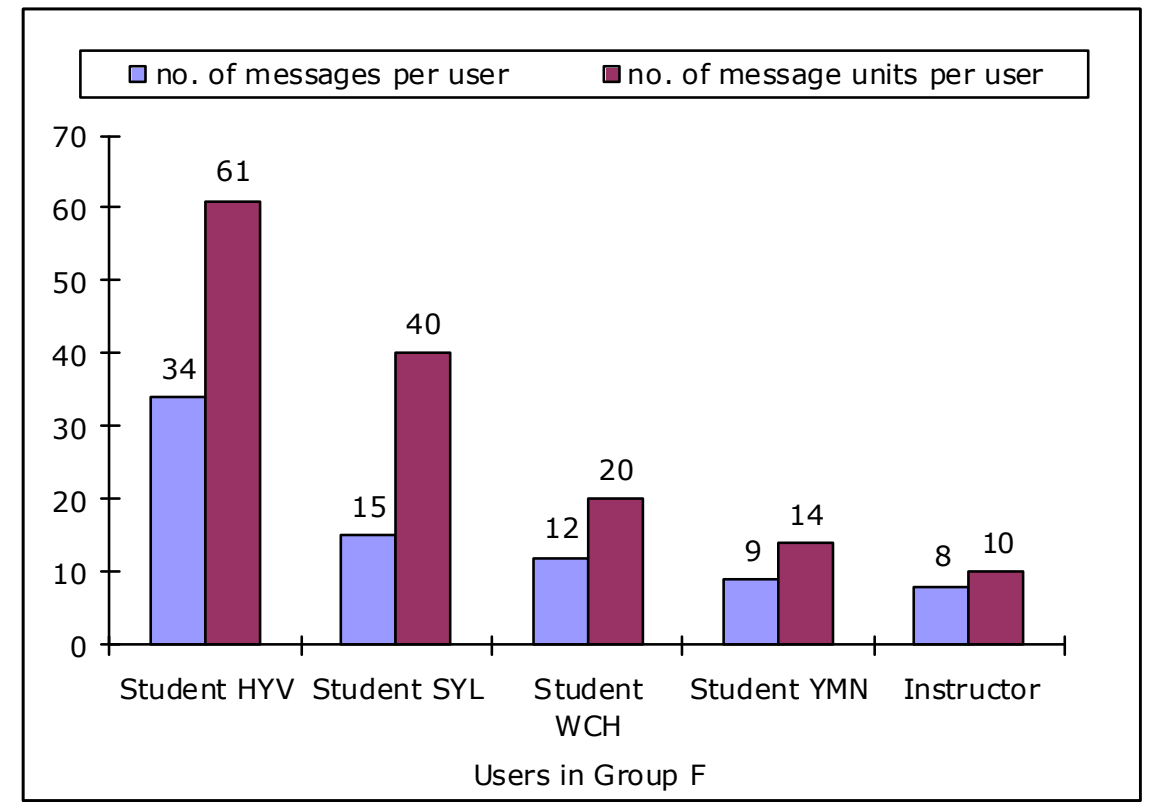

Figure 8 Number of messages and message units per user in Group F

In summary, the data analysed showed how intra-groups operated differently, and yet within discernable patterns, some being strong contributors, while others offered little support to their peers. It was found that students of Group A and B were actively engaged in the collaborative task and their interaction was rich with the ir load evenly shared among the members. Group D showed the 
group was more passively engaged in the discourse which might be attributed to their full-time student status, where traditionally there was a lot of face-to-face communication.

\section{Threaded messages}

In general, the postings that formed a thread stayed on the topic. To capture and show the patterns of connection among the units of analysis, a visual mapping of all the units is presented below (Figures 9 - 13) to reveal whether the students commented and responded to each other's ideas.

Based on the visual mapping in Figure 9,25 threaded messages from Group A were identif ied from the 109 messages with $32 \%$ being regarded as active threads (a threaded message with 4 to 10 referents, going deeper to a level of 2 to 5), indicating that learners were actively engaged in the discussion, cooperative ly assisting each other.

Key: $\mathbf{O}=$ Original message $\mathrm{R}=$ Response message

\begin{tabular}{|c|c|c|c|c|c|}
\hline $\begin{array}{l}0 \\
\text { R }\end{array}$ & $\begin{array}{c}0 \\
R \\
R\end{array}$ & $\frac{0}{R R R}$ & $\begin{array}{l}0 \\
R \\
R\end{array}$ & $\begin{array}{c}\text { O) } \\
R \\
R \\
R\end{array}$ & $\begin{array}{c}0 \\
R(R \\
R(R\end{array}$ \\
\hline 11 messages & 2 messages & 2 messages & 1 message & 1 message & 2 messages \\
\hline$\frac{0}{R R} R$ & $\frac{0}{R R R}$ & $\begin{array}{c}0 \\
R \\
R \\
R\end{array}$ & 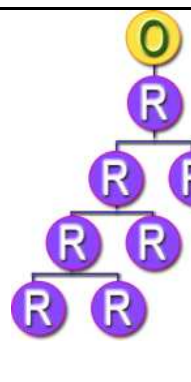 & $\begin{array}{l}\text { O) } \\
\text { R } \\
\text { R } R \\
R \\
R \\
R \\
R\end{array}$ & 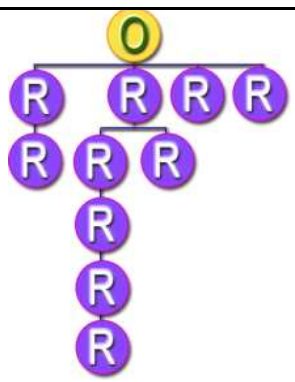 \\
\hline 1 message & 1 message & 1 message & 1 message & 1 message & 1 message \\
\hline
\end{tabular}

Figure 9. Threaded messages ge ne rated from pos tings of Group A

Based on the visual mapping in Figure 10, 57 threaded messages from Group B were identified from 276 messages, with $47 \%$ being regarded as active threads (a threaded message with 4 to 13 referents, going deeper to a level of 2 to 5), indicating heated discussion was taking place, with ample scaffolding among the members provided. 


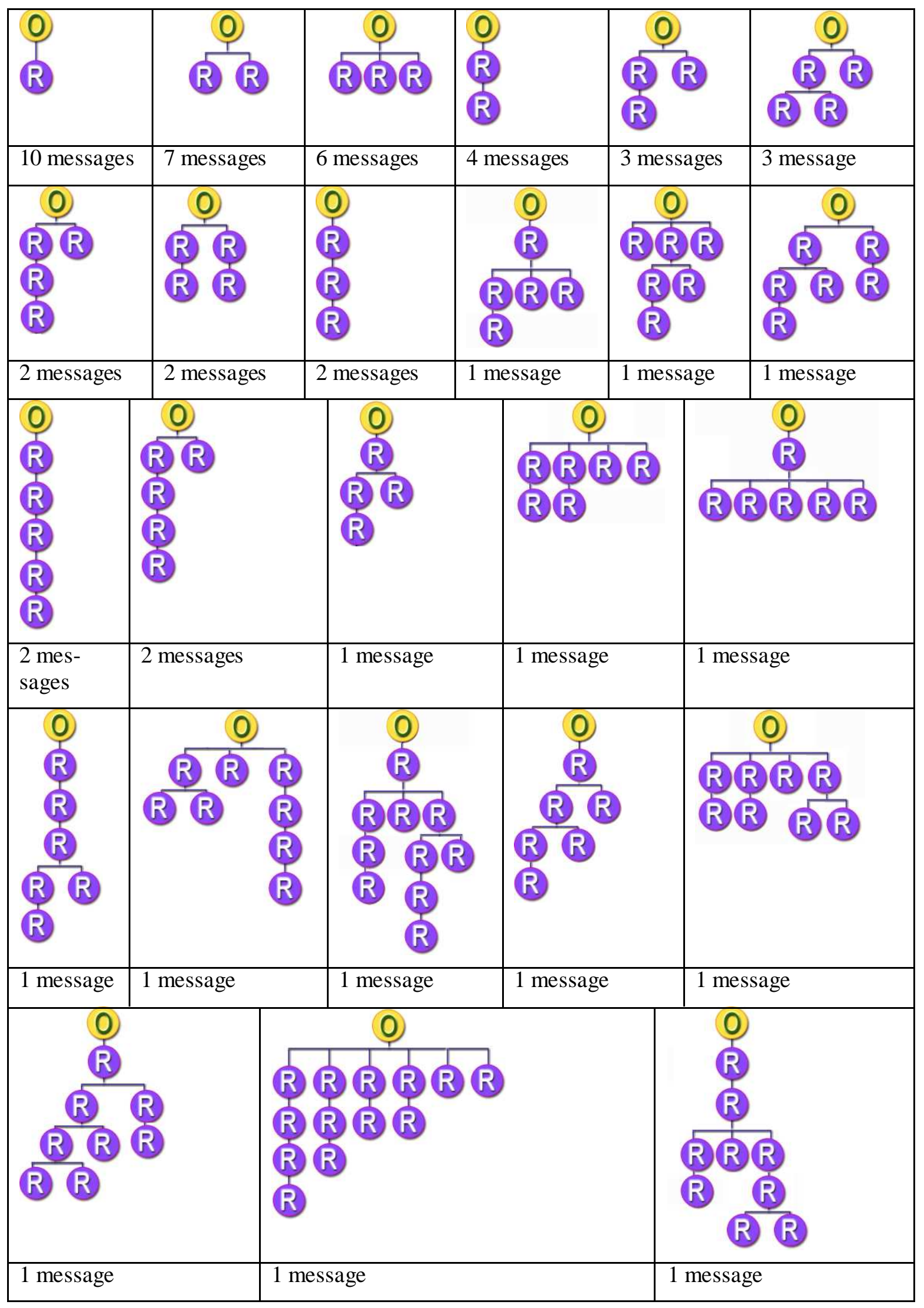

Figure 10. Threaded mess ages generated from postings of Group B 
Based on the visual mapping in Figure 11, 14 threaded messages from Group C were identified from 64 messages with $35 \%$ being regarded as active threads (a threaded message with 4 to 9 referents, going deeper to level 3), indicating that the members interacted and collaborated.

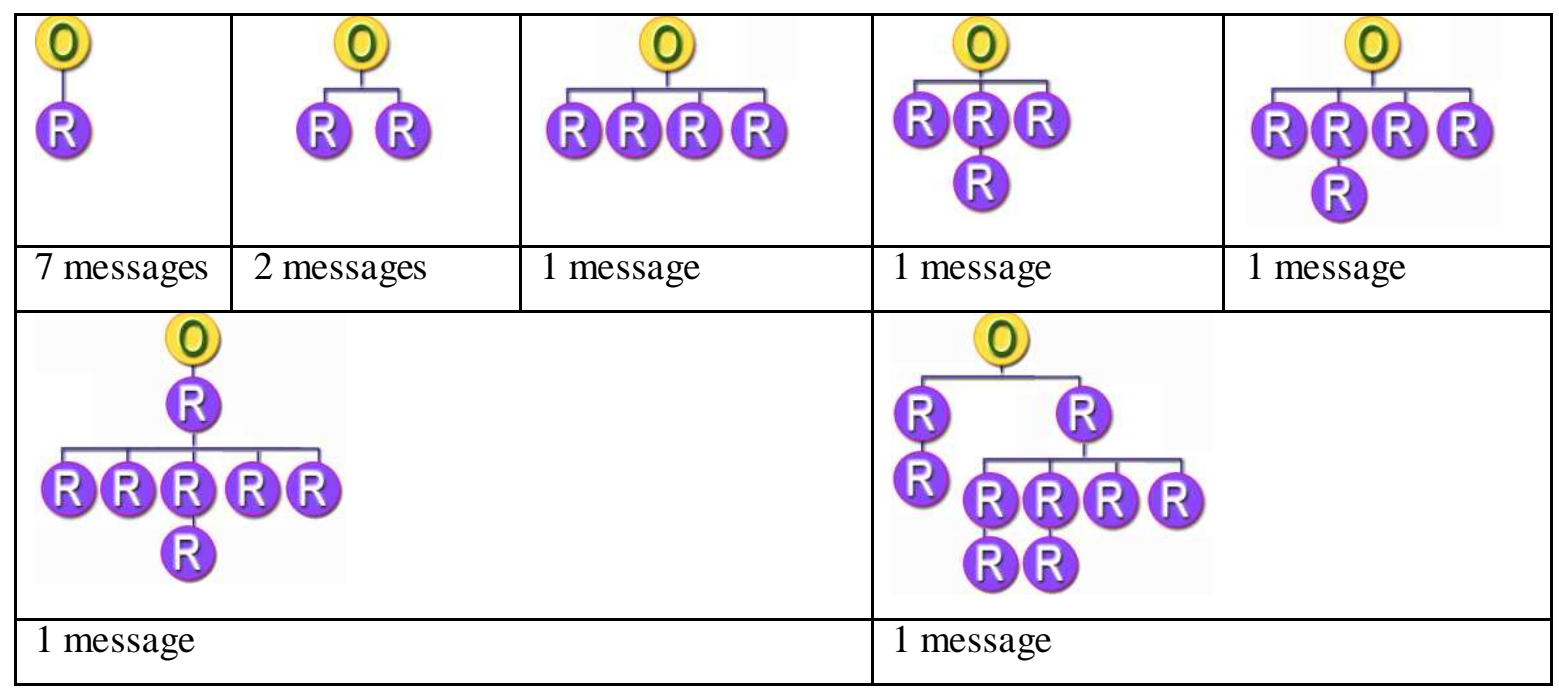

Figure 11.Threaded messages ge ne rated from pos tings of Group $\mathrm{C}$

Based on the visual mapping in Figure 12, 19 individual messages and 6 threaded messages from Group D were identified from 34 messages where $66.6 \%$ of the threaded messages did not go deeper than level 1, indicating that the members were reluctant to collaborate and each received little input from the ir peers.

\begin{tabular}{|l|l|l|}
\hline $\mathbf{O}$ & $\mathrm{O}$ & $\mathrm{O}$ \\
$\mathrm{R}$ & $\mathrm{R}$ & $\mathrm{R}$ \\
$\mathrm{R}$ & $\mathrm{R}$ \\
\hline 4 messages & 1 message & 1 message \\
\hline
\end{tabular}

Figure 12. Threaded mess ages ge nerated from postings of Group D 


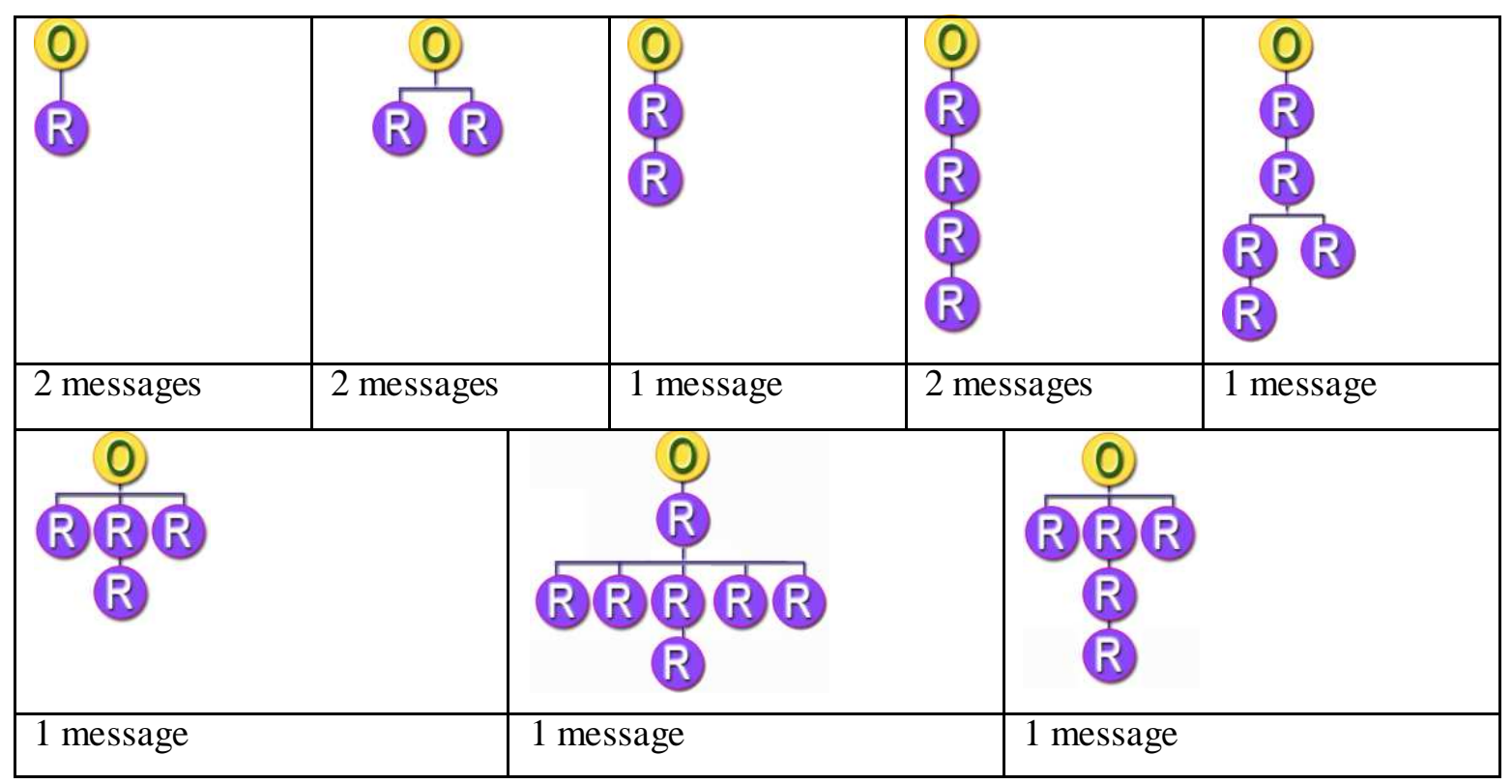

Figure 13. Threaded mess ages ge nerated from postings of Group $\mathrm{E}$

Based on the visual mapping in Figure 13, 17 individual messages and 11 threaded messages from Group E were identified from 64 messages with $54 \%$ being regarded as active threads (a threaded message with 4 to 7 referents, going deeper from level 2 to level 4), indicating that the members were willing to collaborate but did not receive adequate support from the group.

In summary, engagement of members in the learning community varied significantly. A total of 36 messages were not referenced further with 19 and 17 non-referenced messages identified in group $\mathrm{D}$ and $\mathrm{E}$ respectively. Closer examination of the discourse showed that most participants sent new messages in these two groups in which there were hardly any responses sent as a reply to a certain message. Further, most of the threaded messages identified in group D were linear and showed little interaction as $66.6 \%$ of the discussion threads did not go deeper than level one. There was the possibility that the learning community was not established in Group D as there were low levels of social interaction and insufficient support being rendered to scaffold learning among the members. In contrast, Group A and Group B generated threaded messages with most intensive interaction in which $32 \%$ and $47 \%$ were regarded as active threads respectively. In itself, this feature was evidence of high levels of social interaction and collaboration, contributing to the establishment of the community of learning.

\section{Nature of Participation}

To understand the nature of participation, the messages were further divided into coded thematic units where each unit contained one idea. The coded units of messages were further classified into four main categories based on Henri's (1992) model, namely: administrative, technical, social, and content as presented in Table 5 and Figure 14. 
Table 5. Distribution of coded messages showing the nature of participation of Groups A-F

\begin{tabular}{llllll}
\hline & Adminis trative & Technical & Social & Content & Total \\
\hline Group A & 12 & 28 & 31 & 145 & 216 \\
\hline Group B & 21 & 80 & 171 & 241 & 513 \\
\hline Group C & 17 & 11 & 27 & 103 & 158 \\
\hline Group D & 19 & 6 & 23 & 44 & 92 \\
\hline Group E & 11 & 15 & 56 & 58 & 140 \\
\hline Group F & 10 & 4 & 43 & 88 & 145 \\
\hline
\end{tabular}

The findings in Figure 14 revealed that nearly half of the messages related to content, revealing that learners' main focus was the discussion relating to their collaborative tasks. Group E and Group D received most administrative messages from the facilitators, indicating that they required most support. Groups A, B, and E posted most technical messages, and their experience with technology was worth investigation. Group B and E posted a huge number of social messages accounting for $33.3 \%$ and $40 \%$ of the total messages respectively, and their impact on interactivity and learning in the CSCL environment deserved our attention.

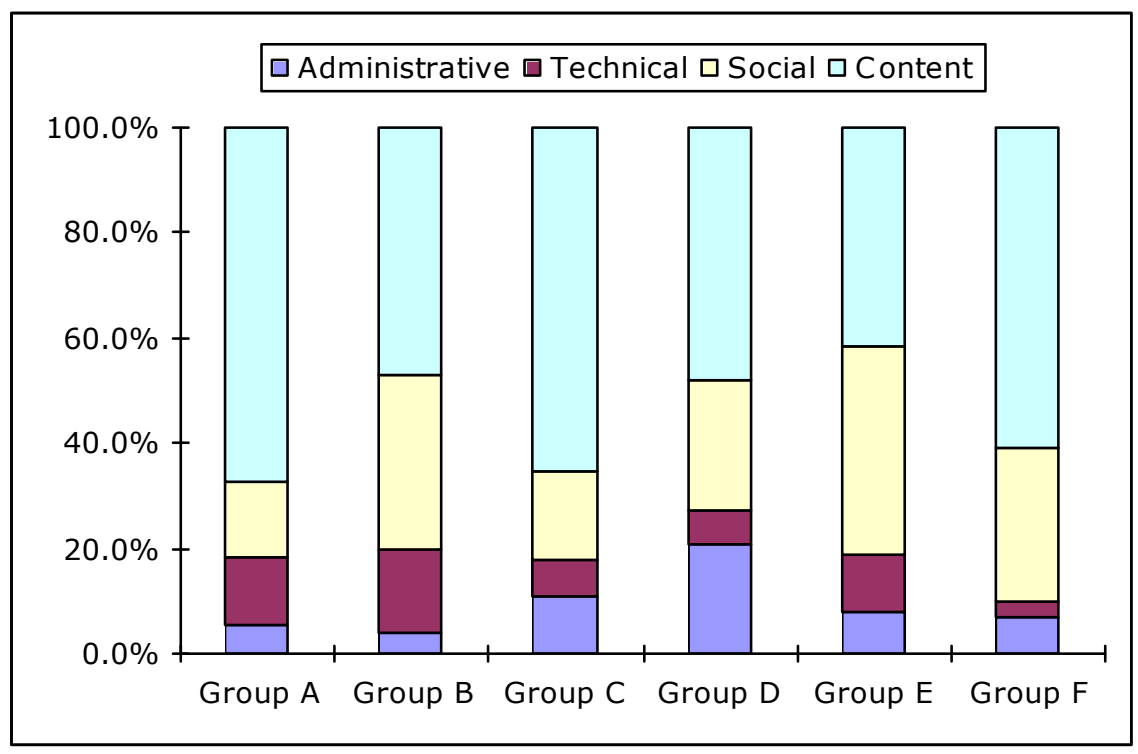

Figure 14 Distribution of coded messages showing the nature of participation of Groups A-F by percentage

The analysis conducted so far on the level, intensity and nature of participation illuminates some data on the interactive patterns among the groups but it does not reveal detail on how such patterns of interaction contributed to learning. The next section will thus focus on this aspect. 


\section{Social Co-construction of Knowledge and Higher Order Thinking Skills}

The coded thematic units classified as content were further divided into five categories based on Gunawardena et al.'s (1997) model. This model evaluates the social construction of knowledge in online discussion forums and distinguishes between five phases of knowledge construction, from Phase I to Phase V, indicating progress from the lower to higher mental functions and revealing how learners contribute toward the construction of know ledge:

Phase I: Sharing/comparing of information

Phase II: Discovery of dissonance

Phase III: Negotiation of meaning/Co-construction of know ledge

Phase IV: Testing tentative constructions

Phase V: Agreement statement/applications of newly constructed meaning.

As the assessment design of the collaborative task was in terms of a group project, there were some coded message units that students discussed about the presentation of their content. These units did not fall into any of the Phases mentioned above. They were classified as others as shown in Table 6 and Figure 15.

Table 6. Summary of analysis of content mess age units by percentage of units at each phase of knowle dge construction for Groups A-F

\begin{tabular}{|c|c|c|c|c|c|c|c|}
\hline \multicolumn{8}{|c|}{ Content message units (pe rce ntage) } \\
\hline & \multicolumn{6}{|c|}{ Phases } & \multirow[b]{2}{*}{ Total } \\
\hline & $\mathbf{I}$ & II & III & IV & $\overline{\mathbf{V}}$ & Others & \\
\hline Group A & $24.8 \%$ & $13.1 \%$ & $19.3 \%$ & $5.5 \%$ & $13.1 \%$ & $24.1 \%$ & $100.0 \%$ \\
\hline Group B & $14.9 \%$ & $12.9 \%$ & $7.1 \%$ & $3.3 \%$ & $1.2 \%$ & $60.6 \%$ & $100.0 \%$ \\
\hline Group C & $35.9 \%$ & $7.8 \%$ & $2.9 \%$ & $4.9 \%$ & $1.9 \%$ & $46.6 \%$ & $100.0 \%$ \\
\hline Group D & $27.3 \%$ & $4.5 \%$ & $6.8 \%$ & $2.3 \%$ & $0.0 \%$ & $59.1 \%$ & $100.0 \%$ \\
\hline Group E & $39.7 \%$ & $5.2 \%$ & $10.3 \%$ & $3.4 \%$ & $0.0 \%$ & $41.4 \%$ & $100.0 \%$ \\
\hline Group F & $25.0 \%$ & $13.6 \%$ & $4.5 \%$ & $1.1 \%$ & $0.0 \%$ & $55.7 \%$ & $100.0 \%$ \\
\hline
\end{tabular}




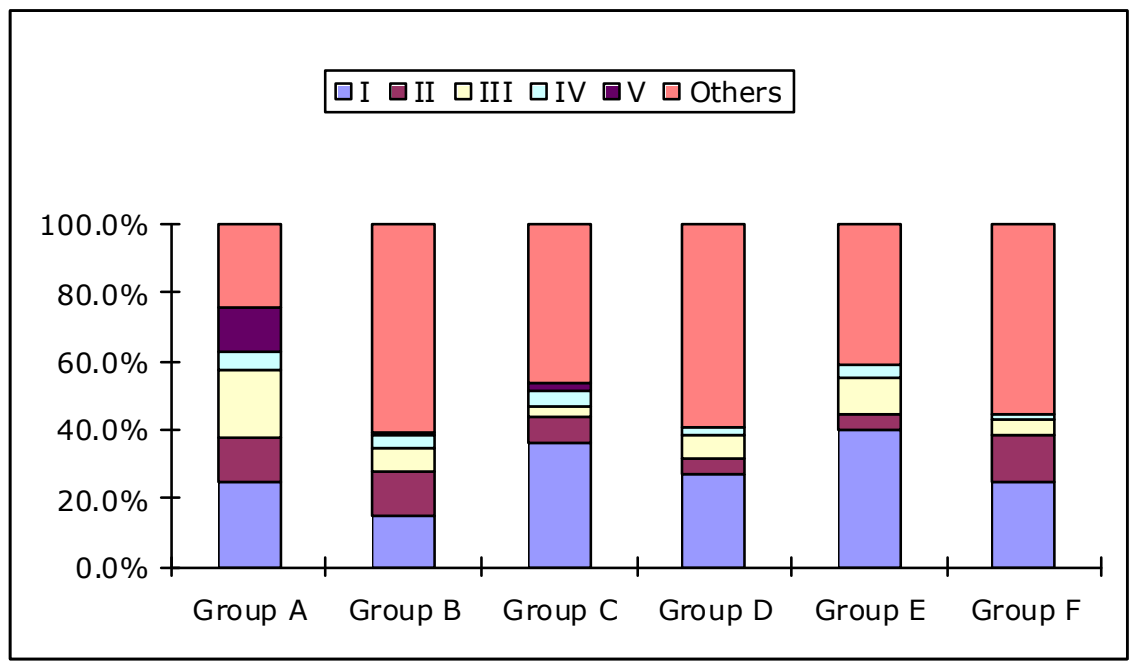

\section{Figure 15. Summary of analysis of content message units by percentage of units at each phase of knowle dge construction for Groups A-F}

Data analysed in Table 6 and Figure 15 suggests some clear patterns over the five phases of the activity. Most of the communication (14-39\%) among the group members remained in the phase of sharing or comparing information (Phase 1). This was somewhat expected because such a phase of learning would provide the foundation for further exploration. 4-13\% and 3-19\% of the written messages were categorised as Phase II and Phase III respectively, which showed evidence of a considerable amount of co-constructed knowledge, critical analysis of peer ideas, or instances of negotiation taking place. Statements contributing to Phases IV and V, however, dropped significantly to $1-5 \%$ in which no statements belonging to Phase V were identified in Group D, E, and F. The learning community of Group D, E, and F, as a whole, did not appear to foster much testing and application of new ideas, which were fundamental processes to construction of higher order thinking skills.

Amongst all groups, Group A demonstrated that they were cognitively engaged with high quality interactions that occurred in the discussion forum, contributing to know ledge creation with as high as $19.3 \%$ of the written messages related to negotiation of meaning and $13.1 \%$ of the statements promoting cognitive change. The following excerpt from group A is presented as an example of students' collaborative know ledge construction activity in the CSCL environment. This example illustrates how the students participating in this study collaboratively processed an explanation of time, constructed a representation, and advanced in explaining the phenomena. Building knowledge required the students to consciously confront the ir previous knowledge and the possible misconceptions and to develop more coherent and examined explanations by cons idering the new evidence presented in the learning situation.

Excerpt from Group A illustrating five different phases of knowledge construction activity in the CSCL environment:

Phase I: Sharing/comparing of information

For the product sample, we can try to collect some wipers. According to the information we gathered, it (micro fiber) is a very ideal material for producing wiper because of its little hooks. Those hooks can hold a lot of dust. Do you agree? (GA-109/C14)

Phase II: Discovery of dissonance

I think we don't need to give an example for each property of the micro fiber. (GA-109/C113) 
Phase III: Negotiation/Co-construction

Are the adhesiveness and absorbing ability meaning the same thing? Shall we use wiper or glass cleaning cloth as an example? Is the absorbing effect is the same as those product that can absorb facial oil quickly? Shall we use the modern handkerchieffor lady as an example in here? (GA-109/C101)

Phase IV: Testing tentative constructions

In addition, can we produce a short video explaining the absorbing power of the micro fiber wiper (just similar to an advertisement that shows a comparison of several products), and show its properties and usage? (GA-109/C76)

Phase V: Agreement statement/applications of newly constructed meaning

Bleaching agent could not be added when washing micro fiber product because the chemicals in the bleaching agent may break down the micro fiber. We add detergent when using wiper (non-micro fiber product), because the detergent can help to remove dust, stains or oil. As the micro fiber product can remove dust, stains or oil by itself so detergent is not needed. (GA-109/C89)

The excerpt illustrates how the intensive social interaction contributes to the cognitive change, evolving from processing of data to co-construction of knowledge, revealing that higher order thinking had been promoted among learners in the community.

\section{Discussion}

The Activity System framework (Engeström, 1987) used in this study is useful for bringing together a wide range of factors that impact on the learning activity. To align with the theoretical framework, the following pair of attributes, interactivity versus cognitive presence, will be discussed based on the findings to examine how interactivity, social presence and teaching presence have contributed to effective cognitive learning in the CSCL community.

The analysis of partic ipation levels indicated that the discussion forum was used often by most groups who contributed regularly. The discussion was highly interactive as evidenced by the majority of direct responses and commentaries to messages, rather than postings of independent statements. The discussion forum was evidently used for social interaction, administration, and technical support. Findings also suggested that the quality of interaction significantly impacted the quality of cognitive learning constructed by the group. Taking Group A and Group D as illustrative examples for discussion, there appears to be a positive relationship between the quality of collaborative process engaged in by the groups and the quality of cognitive skills fostered.

Group A posted the second highest numbers of messages (115 valid messages) with character length from 9 to 541 characters during the 7 week project duration. Their intra-group discussion was commonly conducted during the period between 10 p.m. and 12 a.m., revealing their preference to collaborate after work and family business in the evening.

Interactions among the members were intensive and rich as all of their messages were threaded, and with more than $32 \%$ of the threaded messages containing 4 to 10 referents, showing two to five levels of discourse. Members of Group A promoted each other's understanding through online support, help, and encouragement. It was common to observe that if a member of the group did not understand the solution to a problem, his or her team-mates sent reinforcing messages to address his or her misunderstanding before the group moved on. Ensuring that each member of the group receives the help they needs from their peers is key to promoting effective collaboration interaction.

Furthermore, most of the members participated actively in the collaborative tasks with the ir load evenly shared among the members, cooperative ly assisting each other. When subjects collaborated, they often shared the cognitive burden implied by the task. Spontaneously the group distributed the cognitive subtasks to individual members. Group A, as an activity system, had tried to avoid re- 
dundancies and such division of labour enabled each member to devote more resources to the task allocated to her. The shared cognitive load implied a flexible turn-taking and collaboration within the group (Dillenbourg \& Schneider, 1995). The depth, breadth and spread of the postings among the Group A members indicated that there were high levels of social interaction and collaboration, contributing to the establishment of the community of learning.

The quality interaction generated and maintained within the learning community of Group A impacted significantly on their co-construction knowledge processes with as high as $19.3 \%$ of the written messages relating to negotiation of meaning and $13.1 \%$ promoting cognitive change. The discussion of the strategy to solve the problem assisted the group members to construct a shared view or mental model of the goals and tasks required to be executed. This mental model can improve the coordination, because each member knows how her task fits into the global team goals. The learning potential of a team is maximised when all the students actively participate in the group discussions. Building involvement in group discussions increases the amount of information available to the group, enhancing group decision-making, and improving the students' quality of thought during the learning process. Taking such ideas into consideration, it was evident that Group A had displayed a high level of thinking skills in the proposal and implementation of a solution to tackle the problems faced.

Group D interacted differently. They were first year full-time student-teachers who posted the least number of messages (34 valid messages) during the 7 week project, three times less than those of Group A. Their intra-group discussion was mainly carried out during the period between 12:00 noon and 1:00 pm, reflecting their prerogative to collaborate during lunch time.

Learners in Group D were not as engaged as those of Group A, which was evident in the ir 19 non-referenced individual messages being posted during the 7 week project. Closer examination of the discourse showed that the questions group members did ask each other went unanswered, indicating that there was very little group maintenance and task management activity when compared to Group A. Furthermore, most of the threaded messages identified in Group D were quite linear and showed poor interaction as $66.6 \%$ of the discussion threads did not go deeper than level one discourse.

Members of Group D were not engaged in the collaborative tasks with their load evenly shared among the members, so they did not share their cognitive burden implied by the task. The depth, breadth and spread of the postings among the Group D members indicated that there were low levels of social interaction and collaboration, and there was the possibility that a learning community was not established in this group.

The unfocused interaction within Group D adversely affected the knowledge construction process. More than $59 \%$ of the statements were classified as "others" and $27.3 \%$ of the statements were categorised as Phase I of sharing information. Only $2.3 \%$ of statements contributed to Phase IV, which was much less than those of Group A. No statements of Phase V category were identified for Group D whereas $13.1 \%$ of statements were identified as Phase V for Group A. This revealed that Group D had acquired surface knowledge only and failed to demonstrate any higher order thinking skills.

The reasons accounting for the lack of interaction among the members of Group D may have been due to technical difficulties, insufficient facilitator scaffolding and/or the failure to establish a harmonious learning environment which will be further explored in the coming papers.

\section{Conclusion}

In conclusion, this study confirmed that there was a positive correlation between the quality of collaborative process engaged by groups and the quality of cognitive skills fostered. High levels of 
social interaction and collaboration contributed to the establishment of a community of learning, nurturing a space for fostering higher order thinking through co-creation of knowledge processes.

It is suggested that the diversified academic background, cultural differences, various life experiences, as well as the geographical distance of the learners should be taken into consideration as well in future discussion. There was the possibility that the mixed-mode learners of in-service teachers (e.g., Group A) might be more know ledgeable, more tactful in interpersonal relationships and more capable of managing time than those of full-time year one learners (e.g., Group D). According to the socio-cultural perspective, this might cause a marked difference in the quality of roles exhibited, such as expert-learner or modelling-mirroring agent in the collaborative learning process. Furthermore, the mixed-mode learners might have a more urgent need to use the discussion forum for collaboration as they were in-service learners whereas the need for interaction for full-time learners might not be that vital as there were still a lot of chances for face-to-face communication on campus. Overall, analyzing the transcripts from the discussion forum had provided useful feedback for module improvement in terms of pedagogical and assessment strategies, design of collaborative tasks, and choice of tools.

This study suggested that the investigative tool provides a useful tool for investigating collaborative learning processes enabled by web-enhanced activities. By applying this model to forum exchanges, it was possible to examine these collaborative learning processes from within the spaces. It was also possible, from coding the range and complexity of the postings, to identify where some further developments to the model could be made.

The proposed analytical framework utilizing different content analysis mode ls to reflect the nature of socio-cultural perspective was found to be useful for evaluating the quality of discourse in the CSCL discussion forum. Assessing the level and intensity of the participation provided a sense of how the participants were using the discussion forum. The analysis of the content of the discussion also contributed to the understanding on how the CSCL process had promoted the mastery of higher order thinking, although some classifications were found to be a bit problematic, in particular, in differentiating the phases of knowledge construction between II and III.

In light of the methodological issues relating to coding reliability, limitations of the investigation in this study are summarized as follows:

- The current study was based on the earlier work of a number of researchers and it was not tested at the empirical level.

- The instruments used were built on small numbers of participants and limited numbers of messages and discussions over a short span of time.

- The selection of the unit of analys is was complex and challenging. Percent agreement on thematic units of analysis was reported and it was impossible to calculate the inter-rater reliability as the unit of analysis varied from phrases, to paragraphs, or the entire posting (Marra et al., 2004). Krippendorf (1980, p.64) concedes that, ultimately, the process of unitization "involves considerable compromise" between meaningfulness, productivity, efficiency, and reliability.

- The coding process was very tedious and time-consuming as some coding tools simply contained too many categories that required excessively fine discriminations. For instance, Gunawardena et al.'s (1997) model includes over twenty categories grouped into five phases. Despite the fact that some qualitative analys is packages such as Atlas/ti®, NUD*IST® and HyperQual® allow coding to be automated based upon multi-string text search and pattern matching, Chinese text with different linguistic structures may urgently require some innovations for computerized coding process. 


\section{References}

Budd, R., Thorp, R., \& Donohew, L. (1967). Content analysis of communications. London: Collier-McMillan.

De Laat, M. (2002). Network and content analysis in an online commun ity discourse [Electronic Version]. In G. Stahl (Ed.), Computer support for collaborative learning: Foundations for a CSCL community (pp. 625-626). Hillsdale, NJ: Lawrence Erlbau m Associates.

De Wever, B., Schellens, T., Valcke, M., \& Van Keer H. (2006). Content analysis schemes to analyze transcripts of online as ynchronous discussion groups: A review. Computers and Education, 46, 6-26.

Dewiyanti, S., Brand-Gruwel, S., Jochems, W., \& Broers, N. J. (2007). Students' experiences with collaborative learning in asynchronous computer-supported collaborative learning environ ments. Computers in Human Behaviour, 23(1), 496-514.

Dillenbourg, P. \& Schneider, D. (1995). International Journal of Educational Telecommunications, 1 (2/3), 131-146.

Engeström, Y. (1987). Learning by expanding: An activity-theoretical approach to developmental research. Helsinki: Orienta-Konsultit.

Ewing, J., \& Miller, D. (2002). A frame work for evaluating computer supported collaborative learning. Educational Technology \& Society, 5(1), 112-118.

Gillies, R. M. (2004). The effects of co-operative learning on junior high schools students during small group learning. Journal of Learning and Instruction, 14(2), 197-213.

Gunawardena, C.N., Lowe, C.A., \& Anderson, T. (1997). Analysis of a global online debate and the development of an interaction analysis model for examining social construction of knowledge in co mputer conferencing. Journal of Educational Computing Research, 17, 397-431.

Gunawardena, C., Carabajal, K., Lowe, C.A. (2001). Critical analysis of models and methods used to evaluate online learn ing networks. American Educational Research Association Annual Meeting. Seattle: A merican Educational Research Association.

Häkkinen, P., Järvelä, S., \& By man, A. (2001). Sharing and making perspectives in web-based conferencing. In P. Dillenbourg, A. Eurelings, \& K. Hakkarainen (Eds.), European perspectives on computer-supported collaborative learning. Proceedings of the First European Conference on CSCL. Maastricht: McLuhan Institute, University of Maastricht.

Henri, F. (1992). Co mputer conferencing and content analysis. In A. R. Kaye (Ed.), Collaborative learning through computer conferencing. The Najadan papers (pp. 117-136). London: Springer-Verlag.

Hew, K. F., \& Cheung, W. S. (2003). Models to evaluate online learning communities of asynchronous discussion forums. Australian Journal of Educational Technology, 19(2), 241-259.

Kreijins, K. \& Kirschner, P. A. (2002). Group awareness widgets for enhancing social interaction in computer-supported collaborative learning environ ments: Design and implementation. Proceedings of $32 \mathrm{nd}$ ASEE/IEEE Frontiers in Education Conference, 134-142. Boston, MA.

Krippendorf, K. (1980). Content analysis: An introduction to its methodology. London: Sage.

Lally, V. (2002). Squaring the circle: Triangulating content and social network analysis with critical event recall. Networked Learning Conference 2002, Sheffield.

Lally, V. \& De Laat, M. (2002). Deciphering individual learning processes in virtual professional development, Networked Learning Conference 2002, Sheffield.

Lamon, M., Reeve, R. \& Scardamalia, M. (2001). Mapping learning and the growth of knowledge in a knowledge building community. Paper presented at the American Educational Research Association Meeting 2001. Seattle, Washington. Retrieved July 2006 fro $\mathrm{m} \mathrm{http://ikit.org/lamon/mapping.html}$ 
Lehtinen, E., Hakkarainen, K., Lipponen, L., Rahikainen, M., \& Muukkonen, H. (2003). Computer supported collaborative learning: A review. Retrieved 29 May 2003 from http://etu.utu.fi/papers/clnet/clnetreport.html

Marra, R. M., Moore, J. L., \& Klimc zak, A. K. (2004). Content analysis of online discussion forums: A comparative analysis of protocols. Educational Technology Research Development, 52, 23-40.

Nach mias, R., Mioduser, D., Oren, A., \& Ram, J. (2000). Web-supported emergent-collaboration in higher education courses. Educational Technology \& Society, 3(3), 94-104.

Resta, P., \& Laferriere, T. (2007). Technology in support of collaborative learning. Educational Psychology Review, 19, 65-83.

Rourke, L., Anderson, T., Garrison, D.R., \& Archer, W. (2001). Methodological issues in the content analysis of computer conference transcripts. International Joumal of Artificial Intelligence in Education, 12, 1-17.

Shellens, T., \& Valcke, M. (2005). Collaborative learning in asynchronous discussion groups: What about the impact on cognitive process? Computers in Human Behaviour, 21(6), 957-975.

Smith, R. (2003). Learning in virtual teams: A summary of current literature. Retrieved 1 February 2003 from https://www.msu.edu/ s mithre9/Project12.htm

Strijbos. J. W., Martens, R. L., Prins, F. J., \& Jochems, W. M. G. (2006). Content analysis: What are they talking about? Computers \& Education, 46, 29-48.

Warschauer, M. (1997). Co mputer-mediated collaborative learning: Theory and practice. Modern Language Journal, 81(3), 470-481.

\section{Biography}

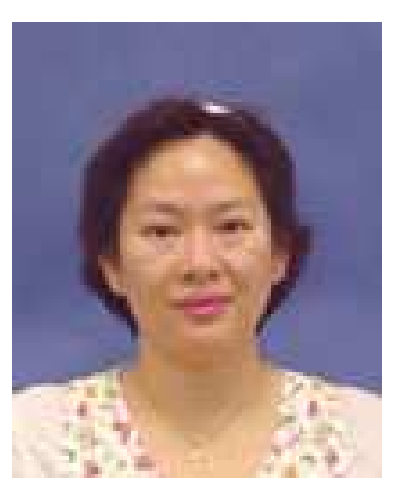

Dr. Ada Ma is the assistant professor of Technology and Living Division of the Department of Mathematics, Science, Social Sciences and Technology, at the Hong Kong Institute of Education. She is currently teaching Technology and Living with a focus on textiles for both full-time and part-time Bachelor Degree programmes. She is interested in various research areas such as computer-supported collaborative learning, textiles education, curriculum innovations, assessment, lifelong learning and gender issues. She has participated actively in various academic activities ranging from publication of conference proceedings, journals and book chapters to being a research investigator of internal and external funded projects. 